\title{
Evidence that autonomic mechanisms contribute to the adaptive increase in insulin secretion during dexamethasone-induced insulin resistance in humans
}

\author{
B. Ahrén
}

Received: 24 January 2008 / Accepted: 11 March 2008 / Published online: 24 April 2008

(C) Springer-Verlag 2008

\begin{abstract}
Aims/hypothesis This study examined whether autonomic mechanisms contribute to adaptively increased insulin secretion in insulin-resistant humans, as has been proposed from studies in animals.

Methods Insulin secretion was evaluated before and after induction of insulin resistance with or without interruption of neural transmission. Insulin resistance was induced by dexamethasone ( $15 \mathrm{mg}$ given over 3 days) in nine healthy women (age 67 years, BMI $25.2 \pm 3.4 \mathrm{~kg} / \mathrm{m}^{2}$, fasting glucose $5.1 \pm$ $0.4 \mathrm{mmol} / \mathrm{l}$, fasting insulin $46 \pm 6 \mathrm{pmol} / \mathrm{l})$. Insulin secretion was evaluated as the insulin response to intravenous arginine $(5 \mathrm{~g})$ injected at fasting glucose and after raising glucose to 13 to $15 \mathrm{mmol} / 1$ or to $>28 \mathrm{mmol} / 1$. Neural transmission across the ganglia was interrupted by infusion of trimethaphan $\left(0.3-0.6 \mathrm{mg} \mathrm{kg}^{-1} \mathrm{~min}^{-1}\right)$.

Results As an indication of insulin resistance, dexamethasone increased fasting insulin (to $75 \pm 8 \mathrm{pmol} / 1, p<0.001$ ) without significantly affecting fasting glucose. Arginine-induced insulin secretion was increased by dexamethasone at all glucose levels (by $64 \pm 12 \%$ at fasting glucose, by $80 \pm$ $19 \%$ at $13-15 \mathrm{mmol}$ glucose and by $43 \pm 12 \%$ at $>28 \mathrm{mmol}$ glucose; $p<0.001$ for all). During dexamethasone-induced insulin resistance, trimethaphan reduced the insulin response to arginine at all three glucose levels. The augmentation of the arginine-induced insulin responses by dexamethasoneinduced insulin resistance was reduced by trimethaphan by $48 \pm 6 \%$ at fasting glucose, $61 \pm 8 \%$ at $13-15 \mathrm{mmol} / \mathrm{l}$ glucose and $62 \pm 8 \%$ at $>28 \mathrm{mmol} / 1$ glucose $(p<0.001$ for all). In
\end{abstract}

B. Ahrén $(\bowtie)$

Department of Clinical Sciences, Lund University,

B11 BMC, Sölvegatan 19,

22184 Lund, Sweden

e-mail: Bo.Ahren@med.lu.se contrast, trimethaphan did not affect insulin secretion before dexamethasone was given.

Conclusions/interpretations Autonomic mechanisms contribute to the adaptative increase in insulin secretion in dexamethasone-induced insulin resistance in healthy participants.

Keywords Autonomic nerves - Dexamethasone · Humans · Insulin secretion · Parasympathetic nerves · Trimethaphan
Abbreviations
AIR acute insulin response to arginine
$S_{\text {I }} \quad$ insulin sensitivity index
PP pancreatic polypeptide

\section{Introduction}

Insulin secretion is increased by insulin resistance [1-3]. This compensation is of critical importance, because a failure of the islets to adequately respond with increased insulin secretion in insulin resistance is a key factor in the development of type 2 diabetes [4-6]. The mechanisms whereby islets compensate by increasing insulin secretion in the presence of insulin resistance are not established. One potential mechanism might be hyperglycaemia. There is, however, limited support for such a hypothesis, because if the islets responded normally to insulin resistance, hyperglycaemia would not arise. This is evident from experimental studies in which insulin resistance has been induced by nicotinic acid or dexamethasone in healthy participants $[7,8]$. Another potential mechanism is elevated levels of NEFA. This is because NEFA, the plasma levels of which are usually elevated in insulin resistance, may stimulate insulin secretion [9]. However, this, too, is an unlikely hypothesis, because long-term 
elevation of plasma NEFA results in beta cell lipotoxicity with impaired insulin secretion as a consequence [10].

A third potential mechanism contributing to hyperinsulinaemia in insulin resistance is stimulation of insulin secretion by the autonomic nerves. It is known that the islets are richly innervated and these nerves are important for the regulation of islet function $[11,12]$. The parasympathetic branch of the autonomic nervous system is particularly powerful in stimulating insulin secretion [11]. Physiologically, this branch of the autonomic nervous system has been thought to be involved in the cephalic phase of insulin secretion after meal ingestion [11]. Studies in insulin resistant $o b / o b$ mice and $f a l f a$ rats have suggested that increased parasympathetic activity may underlie hyperinsulinaemia [13, 14]. In line with this, the insulin secretory response to cholinergic activation is particularly large in mice with diet-induced insulin resistance [15]. However, it is not known whether the autonomic nerves also contribute to increased insulin secretion in insulin resistance in humans.

Indirect evidence that autonomic nerves contribute to islet adaptation in insulin resistance has, however, been proposed in humans. This indirect evidence depends on measurement of circulating levels of pancreatic polypeptide (PP), a hormone that is produced by the islets and whose secretion is controlled by the vagal nerves. Therefore, the plasma level of PP is considered to be a marker and a surrogate for cholinergic activity $[16,17]$. Three studies have independently shown that participants with insulin resistance have high levels of PP $[3,18,19]$. This would therefore support the hypothesis of autonomic nerve involvement in insulin resistanceinduced hyperinsulinaemia. One of these studies showed a significant negative correlation between insulin sensitivity, as obtained by a euglycaemic, hyperinsulinaemic clamp, and plasma PP levels in middle-aged women, i.e., participants with insulin resistance had high PP levels [3]. Another study showed that the PP response to meal ingestion was markedly augmented in insulin-resistant Pima Indians compared with more insulin-sensitive whites [18]. A third study in healthy participants showed a negative correlation between PP levels and the insulin sensitivity index $\left(S_{\mathrm{I}}\right)$ as revealed from an intravenous glucose tolerance test, although this correlation was dependent on intra-abdominal fat [19].

In the present study, we examined the potential contribution of autonomic mechanisms to islet adaptation in insulin resistance by inhibiting the autonomic nervous system in a model of experimentally induced insulin resistance in healthy participants. We inhibited neural transmission by infusing the ganglionic blocker trimethaphan and studied insulin secretion using the glucose-dependent arginine stimulation test, as the model of insulin resistance studied was dexamethasoneinduced insulin secretion. In this model, insulin resistance is experimentally induced by a 3 day treatment with dexamethasone. Trimethaphan impairs neurotransmission across the autonomic ganglia and in the adrenal medulla [20] and has been used previously to evaluate autonomic regulation of islet function [21, 22]. The glucose-dependent argininestimulation test, which allows for estimation of baseline as well as glucose-augmented and maximal insulin secretion, has also been used in previous studies [23, 24]. Finally, short-term dexamethasone treatment has previously been shown to be a model for inducing insulin resistance in humans $[8,25]$. The hypothesis behind this project was therefore that trimethaphan impairs increased insulin secretion in insulin resistance induced by dexamethasone. Such a result would support the notion that autonomic mechanisms play a role in increasing insulin secretion in dexamethasoneinduced insulin resistance in humans.

\section{Methods}

Participants We studied nine postmenopausal white women aged 67 years. The participants belonged to a study population of non-diabetic women who have regularly undergone euglycaemic hyperinsulinaemic clamp tests and tests on insulin secretion in an on-going study that started in 1993. The nine women selected for this study had normal glucose tolerance as evaluated by the $75 \mathrm{~g}$ oral glucose tolerance test (mean $2 \mathrm{~h}$ glucose $7.3 \pm 1.7[$ mean $\pm \mathrm{SD}] \mathrm{mmol} / \mathrm{l}$ ) and an insulin sensitivity, in the three tests undertaken in 1993-1995, 1996-1998 and 2001-2002, that was in the highest quarter of values measured in all 108 women studied. For example, in the 1993-1995 test, the insulin sensitivity of these nine participants was $89.2 \pm 20.1 \mathrm{mmol}$ glucose $\mathrm{kg}^{-1} \mathrm{~min}^{-1}(\mathrm{pmol} / \mathrm{l})^{-1}$ compared with a mean in the entire group of $71.8 \pm 30.5$ [4]. Age of the participants was $67.2 \pm 0.4$ years, body mass index $25.2 \pm 3.4 \mathrm{~kg} / \mathrm{m}^{2}$, fasting plasma glucose $5.1 \pm 0.4 \mathrm{mmol} / \mathrm{l}$ and $\mathrm{HbA}_{1 \mathrm{c}} 4.8 \pm 0.5 \%$. They were all healthy and none was taking any medication known to affect carbohydrate metabolism. The study was approved by the Ethics Committee in Lund and all participants gave written informed consent before the study.

Study design Each participant underwent four separate glucose-dependent arginine-stimulation tests: (1) without any pre-treatment, (2) with a trimethaphan infusion during the test, (3) after a 3 days of oral dexamethasone treatment (Dexacortal, Organon. Oss, the Netherlands; dosage $3 \mathrm{mg}$ in the morning and evening for the 2 days and $3 \mathrm{mg}$ at 0800 hours of the third day, i.e. the day of the glucose-dependent arginine stimulation test), (4) after the dexamethasone treatment period and with a trimethaphan infusion run during the test. Figure 1 shows the temporal relation between the four tests.

Glucose-dependent arginine stimulation test and trimethaphan infusions Insulin secretion was determined with intravenous 


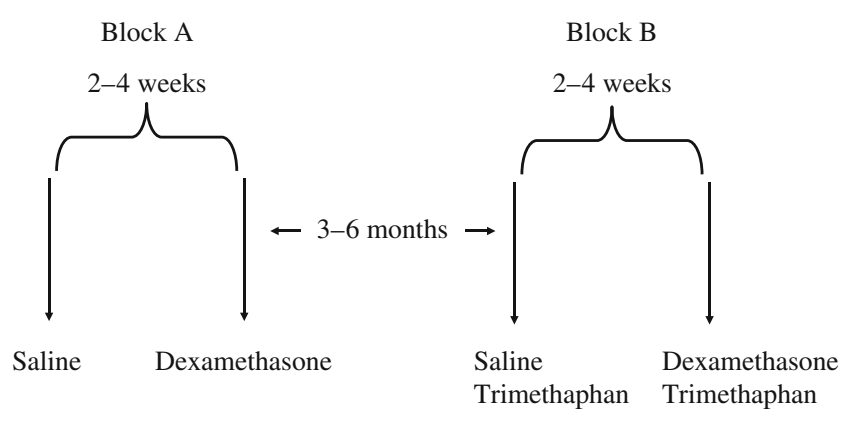

Fig. 1 Glucose-dependent arginine stimulation tests were undertaken on four occasions in blocks of two. In Block A, the first test was undertaken without any dexamethasone and trimethaphan treatment (control test) and after 3 days of treatment with dexamethasone alone. In Block B, tests without (saline) and with dexamethasone were undertaken during intravenous infusion with trimethaphan. Within each block, the two tests were undertaken in the order shown at an interval of 2 to 4 weeks. The two blocks of tests were undertaken in a randomised order 3 to 6 months

arginine stimulation at three glucose levels (fasting, 13-15 and $>28 \mathrm{mmol} / \mathrm{l})$ as previously described $[23,24]$. After an overnight fast, intravenous catheters were inserted into antecubital veins in both arms. One arm was used for the infusion of glucose and the other arm for intermittent sampling. The sampling catheter was kept patent by slow infusion of $0.9 \%(\mathrm{wt} / \mathrm{wt})$ saline when not in use. Baseline samples were taken at -5 and $-2 \mathrm{~min}$. A maximally stimulating dose of arginine hydrochloride $(5 \mathrm{~g})$ was then injected intravenously over $45 \mathrm{~s}$. Samples were taken at 2, 3, 4 and $5 \mathrm{~min}$. A variable-rate $20 \%$ (wt/wt) glucose infusion was then initiated to raise and maintain blood glucose at 13 to $15 \mathrm{mmol} / \mathrm{l}$. Blood glucose was determined every $5 \mathrm{~min}$ at the bedside and the glucose infusion adjusted to reach the desired blood glucose level in 20 to $25 \mathrm{~min}$. New baseline samples were taken, then arginine $(5 \mathrm{~g})$ was again injected and new 2, 3, 4 and 5 min samples were taken. A 2.5-h resting period was then allowed, after which new baseline samples were obtained and a high-speed $(900 \mathrm{ml} / \mathrm{h}) 20 \%$ glucose infusion over 25 to $30 \mathrm{~min}$ was used to raise blood glucose to $>28 \mathrm{mmol} / \mathrm{l}$, as determined at the bedside. At this blood glucose level, new baseline samples were taken and arginine $(5 \mathrm{~g})$ injected followed by final 2, 3, 4 and 5 min samples. During the glucose-dependent arginine-stimulation test, either saline or trimethaphan (Hoffman LaRoche, Nutley, NJ, USA) was infused intravenously. These infusions started $30 \mathrm{~min}$ before the first arginine injection and at $30 \mathrm{~min}$ before the high-speed glucose infusion after the resting period, respectively. The infusions ran until the 5 min sample after the second and third arginine injections, respectively. The initial trimethaphan infusion rate was $0.3 \mathrm{mg} \mathrm{kg}^{-1} \mathrm{~min}^{-1}$; volume infusion rate was $55 \mathrm{ml} / \mathrm{h}$. After $10 \mathrm{~min}$, the infusion rate was increased to $0.45 \mathrm{mg} \mathrm{kg}^{-1} \mathrm{~min}^{-1}$, if systolic blood pressure had not dropped by $10 \mathrm{mmHg}$ (in five participants in both conditions, i.e. with or without dexamethasone); a further increase to $0.6 \mathrm{mg} \mathrm{kg}^{-1} \mathrm{~min}-1$ was made at $20 \mathrm{~min}$ in two participants who had no blood pressure response to trimethaphan. Throughout each experiment, the author was present at bedside to frequently monitor blood pressure and adjust the trimethaphan infusion.

Analyses Blood glucose concentration was determined at the bedside by a device using the glucose dehydrogenase technique (Hemocue, Ängelholm, Sweden). Blood samples for insulin were immediately frozen and serum was frozen at $-20^{\circ} \mathrm{C}$. Serum insulin was analysed with double-antibody RIA technique using guinea pig anti-human insulin antibodies, ${ }^{125}$ I-labelled mono-tyr-human insulin and human insulin standard (Linco, St Charles, MI, USA).

Calculations and statistics Data are presented as mean \pm SEM unless otherwise stated. The acute insulin response to arginine (AIR) was determined as the mean of the 2 to $5 \mathrm{~min}$ samples minus the mean prestimulus insulin concentration at fasting glucose $\left(\mathrm{AIR}_{1}\right)$, at 13 to $15 \mathrm{mmol} / \mathrm{l}$ glucose $\left(\mathrm{AIR}_{2}\right)$ and at $>28 \mathrm{mmol} / 1$ glucose $\left(\mathrm{AIR}_{3}\right)$. The effect of dexamethasone-induced insulin resistance on the three AIRs was calculated by subtracting the $\mathrm{AIR}_{1}, \mathrm{AIR}_{2}$ and $\mathrm{AIR}_{3}$ during the control tests (i.e. without dexamethasone) from the respective AIRs after dexamethasone treatment during the two experimental conditions (i.e. without versus with trimethaphan infusion); this was called $\Delta$ insulin secretion ( $\triangle$ AIR). Statistical analyses were performed with SPSS for Windows (SPSS, Chicago, IL, USA). Differences in $\triangle$ AIR with versus without trimethaphan were determined by paired non-parametric statistics.

\section{Results}

Baseline conditions There were no adverse events during the trimethaphan infusions or dexamethasone administration. Systolic blood pressure was reduced from $131 \pm 8 \mathrm{mmHg}$ to $121 \pm 7 \mathrm{mmHg}$ by trimethaphan $(p=0.03)$. Systolic blood pressure recovered to control values at $60 \mathrm{~min}$ after end of trimethaphan infusions. Dexamethasone treatment did not affect the blood pressure changes caused by trimethaphan infusion rates. Fasting serum insulin increased as a result of dexamethasone from $46 \pm 6$ to $75 \pm 8 \mathrm{pmol} / 1 \quad(p<0.001)$. Mean blood glucose levels were unchanged by dexamethasone $(5.0 \pm 0.2$ without versus $5.2 \pm 0.3 \mathrm{mmol} / 1$ with dexamethasone, NS). In three of the nine participants, fasting glucose increased by 0.3 to $0.5 \mathrm{mmol} / \mathrm{l}$ after dexamethasone. Fasting insulin at $30 \mathrm{~min}$ after trimethaphan before dexamethasone was $44 \pm 6 \mathrm{pmol} / \mathrm{l}$ and the corresponding level with trimethaphan after dexamethasone was $68 \pm 7 \mathrm{pmol} / \mathrm{l}$, both being not significantly different values without trimethaphan (NS). Blood glucose for the same time points was $5.1 \pm$ 
$0.3 \mathrm{mmol} / 1$ and $5.1 \pm 0.2 \mathrm{mmol} / \mathrm{l}$, again with no difference from values without trimethaphan. In two of the nine participants, fasting glucose increased by 0.3 to $0.5 \mathrm{mmol} / 1$ after dexamethasone. This shows that dexamethasone increased fasting insulin as a sign of insulin resistance, whereas $30 \mathrm{~min}$ trimethaphan infusion did not affect fasting insulin and glucose levels.

Glucose-dependent arginine-stimulation test Figure 2 shows serum insulin before and at 2, 3, 4 and $5 \mathrm{~min}$ after arginine administration and at the three glucose levels before and after dexamethasone treatment without or with trimethaphan. Calculated AIRs during the three glucose levels are shown as a function of the glucose concentrations (Fig. 2d). The raising of glucose levels from fasting to 13 to $15 \mathrm{mmol} / \mathrm{l}$ increased AIR substantially under all conditions and the further increase in glucose to $>28 \mathrm{mmol} / \mathrm{l}$ further increased the AIR. Figure 2 shows that: (1) dexamethasone increased insulin levels during all three conditions; (2) trimethaphan alone did not affect insulin secretion; and (3) trimethaphan reduced the increase in insulin secretion obtained by dexamethasone. To estimate the increase in insulin secretion during insulin resistance, $\Delta$ insulin secretion was calculated as the augmentation of AIRs after dexamethasone compared a

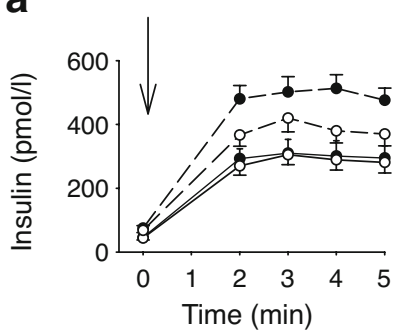

C

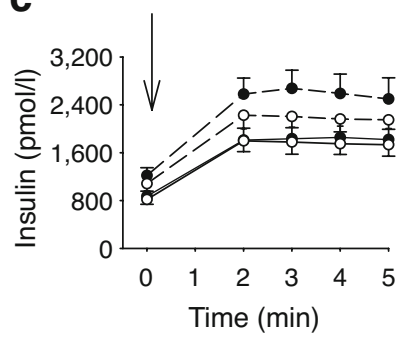

b

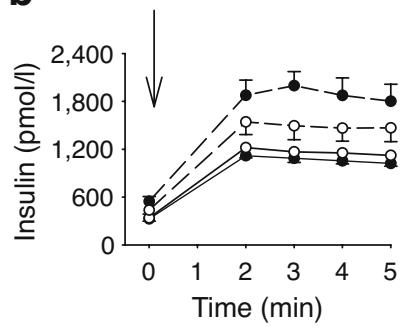

d

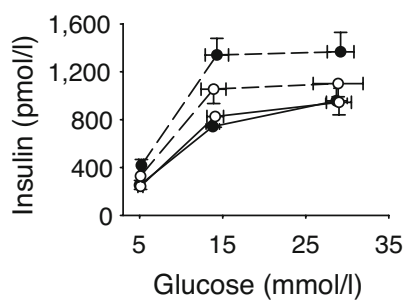

Fig. 2 Insulin levels in nine non-diabetic healthy women before and after intravenous administration of arginine $(5 \mathrm{~g})$ (a) under fasting conditions (glucose $5.1 \pm 0.2 \mathrm{mmol} / \mathrm{l}$ ), (b) after raising glucose levels to 13 to $15 \mathrm{mmol} / 1(14.0 \pm 0.8 \mathrm{mmol} / \mathrm{l})$ and (c) after raising glucose levels to $>28 \mathrm{mmol} / \mathrm{l}(29.0 \pm 0.9 \mathrm{mmol} / \mathrm{l})$. The tests were conducted under baseline conditions (black circles, solid line) or after induction of insulin resistance by dexamethasone (15 mg over 3 days; black circles, dashed line), as well as after infusion of trimethaphan under baseline conditions (white circles, solid line) and after dexamethasone (white circles, dashed line) to impair autonomic neurotransmission. d Suprabasal 2 to $5 \mathrm{~min}$ insulin response to arginine at the three glucose levels versus the glucose levels in the four different tests. Values are means \pm SEM with AIRs without dexamethasone. This $\Delta$ insulin secretion was calculated both without and with trimethaphan. Figure 3 shows that dexamethasone substantially increased $\mathrm{AIR}_{1}$, $\mathrm{AIR}_{2}$ and $\mathrm{AIR}_{3}$. Thus, $\mathrm{AIR}_{1}$ was increased by $64 \pm 12 \%$, $\mathrm{AIR}_{2}$ by $80 \pm 19 \%$ and $\mathrm{AIR}_{3}$ by $43 \pm 12 \%$ during dexamethasone administration. Dexamethasone also increased the AIRs during trimethaphan infusion. Thus, the increase in $\mathrm{AIR}_{1}, \mathrm{AIR}_{2}$ and $\mathrm{AIR}_{3}$ under these conditions was $35 \pm 4,28 \pm$ 4 and $17 \pm 4 \%$, respectively. By comparing the increases in AIRs by dexamethasone without versus those with trimethaphan, a clear impairment was seen for values with trimethaphan, namely $48 \pm 6,61 \pm 8$ and $62 \pm 8 \%$ for $\mathrm{AIR}_{1}$, $\mathrm{AIR}_{2}$ and $\mathrm{AIR}_{3}$, respectively ( $p<0.001$ for all).

\section{Discussion}

The novelty of this study is that it provides direct evidence that the adaptive hypersecretion of insulin in dexamethasoneinduced insulin resistance is dependent on autonomic mechanisms in humans. Previously such a hypothesis has been restricted to experimental animals. Thus, cholinergic antagonism by muscarinic receptor antagonists or truncal vagotomy reduces hyperinsulinaemia in insulin-resistant $o b /$ $o b$ mice [13], falfa rats [26] or rats with experimental lesion in the ventromedial hypothalamus [14, 27]. In humans, we previously reported that the plasma PP level, which is considered an indirect marker of parasympathetic activity $[16,17]$, is negatively correlated to insulin sensitivity over a large range of insulin sensitivity [3]. This would suggest that insulin resistance is accompanied by increased parasympathetic tone.

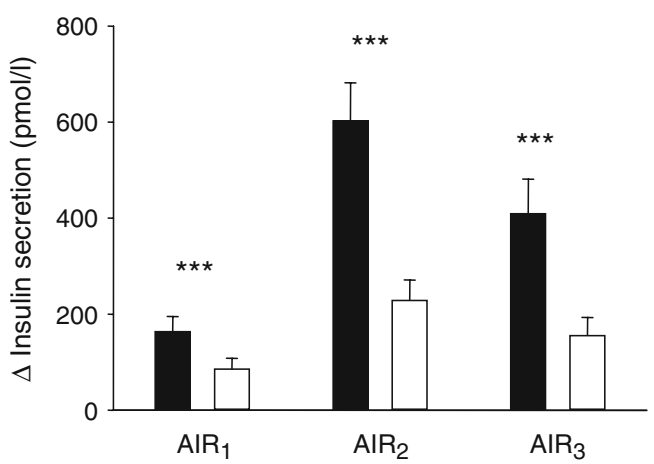

Fig. 3 Insulin secretion in nine non-diabetic healthy women was stimulated by intravenous administration of arginine $(5 \mathrm{~g})$ under fasting conditions $\left(\mathrm{AIR}_{1}\right)$, after raising glucose levels to 13 to $15 \mathrm{mmol} / \mathrm{l}\left(\mathrm{AIR}_{2}\right)$ and after raising glucose levels to $>28 \mathrm{mmol} / \mathrm{l}$ $\left(\mathrm{AIR}_{3}\right)$. The augmented increase $(\Delta)$ in insulin secretion versus baseline conditions without dexamethasone is shown after induction of insulin resistance by dexamethasone ( $15 \mathrm{mg}$ over 3 days) without (black bars) or with (white bars) infusion of trimethaphan. Values are means \pm SEM. $* * * p<0.001$ for probability of random difference between the conditions 
In the present study, dexamethasone was given over 3 days to induce insulin resistance. Glucocorticoid administration is known to induce insulin resistance [8, 25, 28-30]. This is followed by an adaptive increase in insulin secretion $[8,25]$. We previously showed that this adaptation is important for maintaining normoglycaemia, because dexamethasone increased fasting glucose in participants with an inadequate increase in insulin secretion [8]. In that study, participants with an inadequate increase in insulin secretion had had insulin resistance from the beginning, and failed to increase insulin secretion further when a further deterioration of insulin resistance was induced by dexamethasone [8]. To avoid this latter problem, the present study recruited only participants who had high insulin sensitivity from the beginning. This was possible because our participants came from a larger on-going study, in which we undertake regular insulin sensitivity tests by euglycaemic hyperinsulinaemic clamp in healthy participants $[4,31,32]$. We thus selected women with insulin sensitivity in the highest quartile of insulin sensitivity in their age group. Glucocorticoids are also known to inhibit insulin secretion by a direct effect on the beta cells $[33,34]$. Hence, the increase in insulin secretion during dexamethasone-induced insulin resistance is most likely to be due to the adaptive mechanisms rather than to a direct effect of the steroid.

We verified that dexamethasone increased fasting insulin as an indication of insulin resistance. This was accompanied by marked increases in the insulin secretory responses to arginine. To study the contribution of autonomic mechanisms to the adaptive response to dexamethasone-induced insulin resistance, we infused the ganglionic blocker trimethaphan. This interrupts neural transmission across the ganglia. We have previously used this approach to study the contribution of autonomic mechanisms to counter regulatory responses to hypoglycaemia [21] and to the cephalic phase of insulin secretion after meal ingestion [22]. The main finding in the present study is that when infusing trimethaphan after the 3 days of dexamethasone treatment, the augmented arginineinduced insulin secretion was impaired, both at low, medium and high glucose levels. In contrast, as has been shown before [21], the islet response to arginine under baseline conditions was not impaired by trimethaphan. Hence, we conclude that autonomic mechanisms contribute to the increase in insulin secretion that is obtained by dexamethasone-induced insulin resistance.

Our results are restricted to insulin resistance induced by dexamethasone. The question of whether it also applies to insulin resistance in general remains to be studied. Autonomic mechanisms may be different in insulin resistance with different causes, if these are associated with changes in the relative balance between sympathetic and parasympathetic inputs to the islets. It is not known whether such changes are induced by dexamethasone. Nevertheless, our conclusion supports previous reports on animal studies of a neural contribution to insulin hypersecretion in insulin resistance [13, 14, 26, 27]. Our study seems, however, to contradict a recent study of insulin-resistant Pima Indians in which the high PP response but not the high insulin response to meal ingestion was reduced by cholinergic antagonism by atropine [35]. This study would therefore suggest that although the parasympathetic tone to the pancreas is increased in insulin resistance (as indicated by the high PP levels being reduced by atropine), the hyperinsulinaemia would not be dependent on cholinergic activity. Considered in the light of results of the present study, this previous finding would suggest either that there is a difference in the relative contribution of cholinergic input between Pima Indians and Whites, or that dexamethasone-induced insulin resistance elicits a different autonomic response to that seen in Pima Indians. Another possible hypothesis is that the contribution to overall parasympathetic responses by different neurotransmitters is relative. Thus, it is known that the parasympathetic islet nerves harbour not only acetylcholine as the neurotransmitter but also several different neuropeptides [11, 12]. In particular, the neuropeptides vasoactive intestinal polypeptide (VIP), pituitary adenylate cyclise activating polypeptide (PACAP), gastrin releasing polypeptide (GRP) and cocaine-amphetamine regulated transcript (CART) are all islet parasympathetic neuropeptides, the first three of which all have been shown to stimulate insulin secretion [11, 12]. A finding that trimethaphan but not atropine reduces a response, as indicated by the combined results of the present study and that of Pima Indians [35], would therefore suggest that the response is initiated by increased parasympathetic tone but is non-cholinergic and therefore mediated by these neuropeptides. However, this hypothesis needs to be considered in further studies.

The results of this study imply that a stimulus triggered by insulin resistance increases the parasympathetic tone to the islet beta cells to increase insulin secretion and this may contribute to the adaptive hypersecretion of insulin in insulin resistance. Parasympathetic nerves have also been suggested to improve insulin sensitivity, as inferred from studies in which depletion of parasympathetic neurons retroperitoneal fat of animals reduced insulin-mediated glucose uptake [36]. Furthermore, reduced parasympathetic activity has been thought to be associated with insulin resistance in patients with obesity and type 2 diabetes [37]. This would indicate that parasympathetic nerves are important for the regulation of glucose homeostasis both at the peripheral and islet level. However, this needs to be studied in further detail, because trimethaphan interrupts neurotransmission in autonomic ganglia and in the adrenal medulla. Therefore, although the present results indicate that autonomic mechanisms play a role in insulin hypersecretion in dexamethasone-induced insulin resistance, it remains to be established 
whether this is in fact due to the islet autonomic (parasympathetic) nerves.

In conclusion, the increase in insulin secretion by dexamethasone-induced insulin resistance is impaired by interruption of autonomic neurotransmission across the autonomic ganglia. This suggests that neural mechanisms contribute to the adaptive insulin secretion in insulin resistance induced by dexamethasone. The question of whether this is a general phenomenon in insulin resistance and whether it involves the classical neuropeptide acetylcholine or any of the parasympathetic neuropeptides remains to be studied.

Acknowledgements This study was supported by the Swedish Research Council (grant no 14X-6834), Swedish Diabetes Association, Albert Påhlsson Foundation, Region Skåne and the Faculty of Medicine, Lund University. The author is grateful to M. Persson and L. Bengtsson for expert technical assistance.

Duality of interest The author declares that there is no duality of interest associated with this manuscript.

\section{References}

1. Bergman RN, Phillips LS, Cobelli C (1981) Physiologic evaluation of factors controlling glucose tolerance in man. Measurements of insulin sensitivity and B-cell glucose sensitivity from the response to intravenous glucose. J Clin Invest 68:1456-1467

2. Kahn SE, Prigeon RL, McCulloch DK et al (1993) Quantification of the relationship between insulin sensitivity and b-cell function in human subjects. Evidence for a hyperbolic function. Diabetes 42:1663-1672

3. Ahrén B, Pacini G (2005) Islet adaptation to insulin resistance: mechanisms and implications for intervention. Diabetes Obes Metab 7:2-8

4. Larsson H, Ahrén B (1996) Failure to adequately adapt reduced insulin sensitivity with increased insulin secretion in women with impaired glucose tolerance. Diabetologia 39:1099-1107

5. Ahrén B, Pacini G (1997) Impaired adaptation of first-phase insulin secretion in postmenopausal women with glucose intolerance. Am J Physiol 273:E701-E707

6. Weyer C, Bogardus C, Mott DM, Pratley RE (1999) The natural history of insulin secretory dysfunction and insulin resistance in the pathogenesis of type 2 diabetes mellitus. J Clin Invest 104:787-794

7. Kahn SE, Beard JC, Schwartz MW et al (1989) Increased $\beta$-cell secretory capacity as mechanism for islet adaptation to nicotinic acid-induced insulin resistance. Diabetes 38:562-568

8. Larsson H, Ahrén B (1999) Insulin resistant subjects lack islet adaptation to short-term dexamethasone-induced reduction in insulin sensitivity. Diabetologia 42:936-943

9. Dobbins RI, Chester MW, Daniels MB et al (1998) Circulating fatty acids are essential for efficient glucose-stimulated insulin secretion after prolonged fasting in humans. Diabetes 47:1613-1618

10. Zhou VP, Grill VE (1994) Long-term exposure of rat pancreatic islets to fatty acids inhibits glucose-induced insulin secretion and biosynthesis through a glucose fatty acid cycle. J Clin Invest 93:870-876

11. Ahrén B (2000) Autonomic regulation of islet hormone secretionimplications for health and disease. Diabetologia 43:393-410

12. Ahrén B, Wierup N, Sundler F (2006) Neuropeptides and the regulation of islet function. Diabetes 55(Suppl 2):S98-S107
13. Ahrén B, Lundquist I (1982) Modulation of basal insulin secretion in the obese, hyperglycemic, mouse. Metabolism 31:172-179

14. Rohner-Jeanrenaud F, Hochstrasser AC, Jeanrenaud B (1983) Hyperinsulinemia of preobese and obese $f a / f a$ rats is partly vagus nerve mediated. Am J Physiol 244:E317-E322

15. Ahrén B, Sauerberg P, Thomsen C (1999) Increased insulin secretion and normalisation of glucose tolerance by cholinergic agonism in high-fat fed C57BL/6J mice. Am J Phyisol 277:E93-E102

16. Schwartz TW, Holst JJ, Fahrenkrug J (1978) Vagal, cholinergic regulation of pancreatic polypeptide secretion. J Clin Invest 61:781-789

17. Havel PJ, Taborsky GJ Jr (1989) The contribution of the autonomic nervous system to changes of glucagon and insulin secretion during hypoglycaemic stress. Endocr Rev 10:332-350

18. Weyer C, Salbe AD, Lindsay RS (2001) Exaggerated pancreatic polypeptide secretion in Pima Indians: can an increased parasympathetic drive to the pancreas contribute to hyperinsulinemia, obesity, and diabetes in humans? Metabolism 50:223-230

19. Tong J, Utzschneider KM, Carr DB (2007) Plasma pancreatic polypeptide levels are associated with differences in body fat distribution in human subjects. Diabetologia 50:439-442

20. Taylor P (1985) Ganglionic stimulating and blocking agents. In: Gilman AD, Goodman LS, Rall TW, Murad F (eds) The pharmacological basis of therapeutics. MacMillan, New York, pp 215-221

21. Havel PJ, Ahrén B (1997) Activation of autonomic nerves and the adrenal medulla contributes to increased glucagon secretion during moderate insulin-induced hypoglycaemia in women. Diabetes 46:801-807

22. Ahrén B, Holst JJ (2001) The cephalic insulin response to meal ingestion in humans is dependent on both cholinergic and noncholinergic mechanisms and is important for postprandial glycemia. Diabetes 50:1030-1038

23. Ward WK, Bolgiano DC, McKnight B (1984) Diminished B cell secretory capacity in patients with noninsulin-dependent diabetes mellitus. J Clin Invest 74:1318-1328

24. Larsson H, Ahrén B (1998) Glucose-dependent arginine stimulation test for characterization of islet function: studies on reproducibility and priming effect of arginine. Diabetologia 41:1772-1777

25. Beard JC, Halter JB, Best JD et al (1984) Dexamethasone-induced insulin resistance enhances B cell responsiveness to glucose level in normal men. Am J Physiol 247:E592-E596

26. Fletcher JM, McKenzie N (1988) The parasympathetic nervous system and glucocorticoid-mediated hyperinsulinaemia in the genetically obese $/ f a / f a$ ) obese rodents. J Endocrinol 118:87-92

27. Sainsbury A, Rohner-Jeanrenaud F, Cusin I (1977) Chronic central neuropeptide Y infusion in normal rats: status of the hypothalamopituitary-adrenal axis, and vagal mediation of hyperinsulinaemia. Diabetologia 40:1269-1277

28. DePirro R, Bertolli A, Fusco A (1980) Effect of dexamethasone and cortisone on insulin receptors in normal human male. J Clin Endocrinol Metab 51:503-507

29. Groop PH, Groop LC, Tötterman KJ, Fyhrquist F (1987) The effect of dexamethasone on the enteroinsular axis. Scand J Clin Lab Invest 47:491-495

30. Ludvik B, Clodi M, Kautzki-Willer A et al (1993) Effect of dexamethasone on insulin sensitivity, islet amyloid polypeptide and insulin secretion in humans. Diabetologia 36:84-87

31. Larsson H, Ahrén B (2000) Islet dysfunction in insulin resistance involves impaired insulin secretion and increased glucagon secretion in postmenopausal women with impaired glucose tolerance. Diabetes Care 23:650-657

32. Ahrén B, Larsson H (2002) Quantification of insulin secretion in relation to insulin sensitivity in non-diabetic post-menopausal women. Diabetes 52(Suppl 1):S202-S211

33. Lambillotte C, Gilon P, Henquin JC (1997) Direct glucocorticoid inhibition of insulin secretion. An in vitro study of dexamethasone effects in mouse islets. J Clin Invest 99:414-423 
34. Ling ZC, Khan A, Delauyny F et al (1998) Increased glucocorticoid sensitivity in islet beta-cells: effects on glucose-6-phosphatase, glucose cycling and insulin release. Diabetologia 41:634-639

35. Vozarova de Courten B, Weyer C et al (2004) Parasympathetic blockade attenuates augmented pancreatic polypeptide but not insulin secretion in Pima Indians. Diabetes 53:663-671
36. Kreier F, Fliers E, Voshol PJ et al (2002) Selective parasympathetic innervation of subcutaneous and intraabdominal fatfunctional implications. J Clin Invest 110:1243-1250

37. Peterson HR, Rotschild M, Weinberg CR et al (1988) Body fat and the activity of the autonomic nervous system. N Engl J Med 318:1077-1083 